\title{
$20 \mathfrak{x}$ :
}

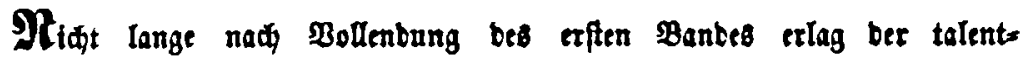
volle Berfafier in bea nod fugenbltaen lebensalter son zwetumbbreiftg

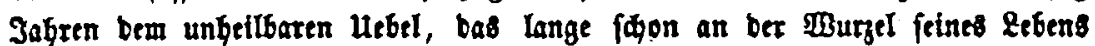
nagte, am 9. SRai 1850, gur Trauter feiner freunbe unb zum Bertult ber

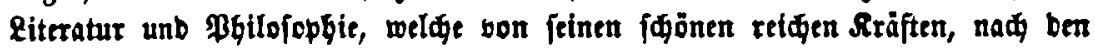
bereits abgelegten Reiftungen, fli now to viel veripreden Eonnte. (Näberes über Danzele Refensgang und Gntwifelung entbält fein Netrolog in ber Malges meinen Beitung som Sabre 1850). TBenn id meinen Bumfa, Danzel per:

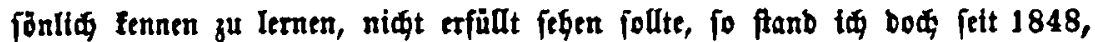
fettbeur ex nemlid in bie Stubien zu Re/ing Reben fid sertift batte, und nad allen Geiten झRaterialien bazu fammelte, mit ifm tm Briefwedffel, unb erbielt

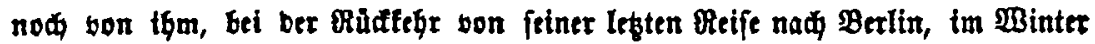
1850, ùber bie retđe 2lusbeute, weldye er für ben gweiten Banb bon bort mite nabm, erfreultăe Ditttheilungen. Ilm fo grȫer war nteine Beftürzung ù6er bie

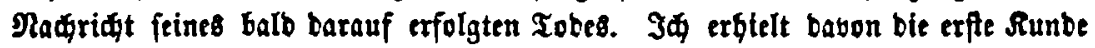
Durdi ben Berleger bes unvollendet geblitbenen Berfes - zugleid mit ber ehrenvollen $\mathfrak{A}$ ufforberung, ben zweiten Banb, mit Benukgung von Danzels binter= Iaffenen Materialien, augzuarbeiten. -

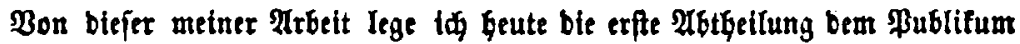

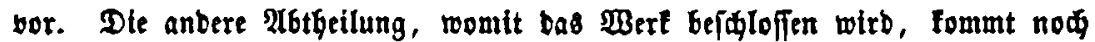
vor 2lblauf Diefes Sabres beraus.

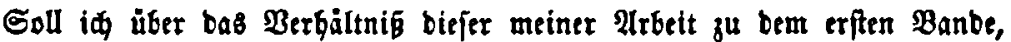
an welden fie fid unmittelbar anfidlieft, ein $\mathfrak{3}$ ort fagen, fo fann es

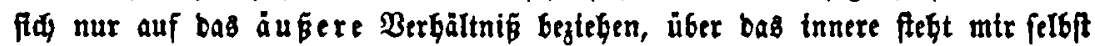

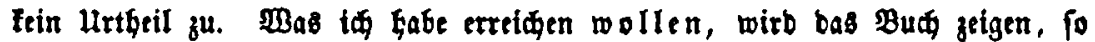
weit id es wirflid erreidit babe. Das eine aber bin id jowogl bem Bet. fafier bes erften Banbes, als mir felbft zu erflären fifulbig, bajabas vorliegente Buad wefentlid tas we ine if. (5s fanben fí in Damels ganjem Ganbidriftliden

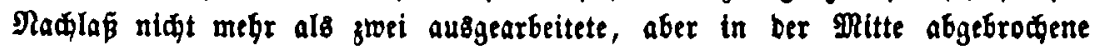

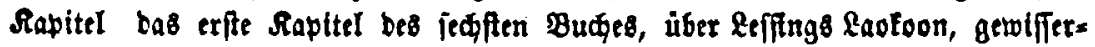

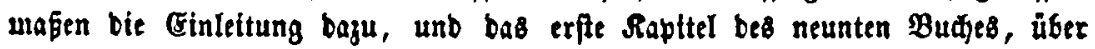
Leffings Pbilojophit. J4 babe nur einen Theil des zulegt genannten Erags mentes zur wörtlidien Einjąaltung in meine 2Arbeit geetgnet gefunben. Ein

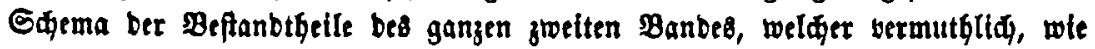

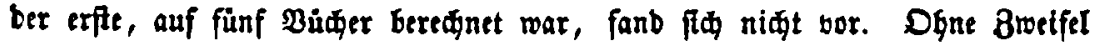
war tiefer \$lan in Danzels sopfe böllig reif unb fertig, unb ba er jebr rafí 
arbeitete, fo würbe ex abrideinlid bet feinen reiden unb georbneten PRaterta* lien tm Laufe bee 3abres fein BBert bollentet baben.

Die mir bon cinem frembe Danzets, Profeffor Dt to $\Im_{a b n}$ in Reibzig, überlieferten Bapiete befteben nun

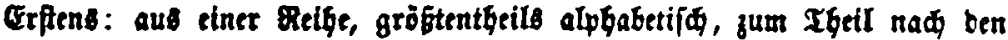

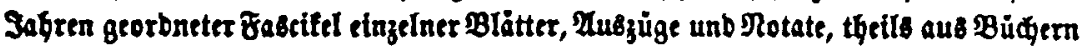

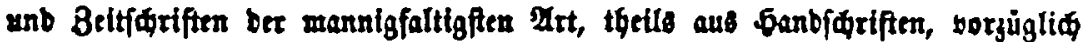
eus ben Gleim'iden gladilafie in Galberfabt unb aus bem ungebrudten Brief=

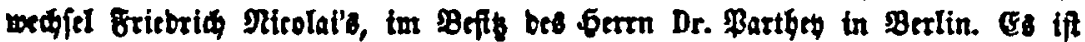
lein Bunlt in \&effings \&eben unb Sajriften, auf welden Danjels betwunberungs:-

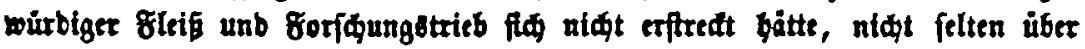
bie son ber Biograbbie geferten und geforberten Cremen binaue. baber berienige, welder eirmal bas 8eitalter 2effings in literarblforijaer \$infidt

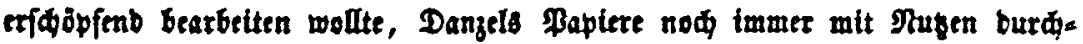
geben wirb. - "Gelneb fileíbeb barf fí tebermana rübmen." Ges wirb mir alfo gefattet fein, binzuzufügen, baß Danzelo Sammlungen in Bezug auf bas Blograpbifde nod eine redit belohnenbe Stadiléfe gefatteten; fa, je zerftreuter unb jufäliger bie Beitrảge biezu auf bem Fellbe ber giteratur beß vorigen $\Im_{a b r=}$ Gunberte exlangt unb gefunben werben, fe weniger werbe if mir einbilben, bas ber Stoff nun wirlliđ auc eríöpft jet.

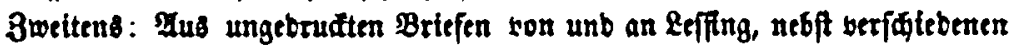
anberen ungebrudten Sdrtiften Re(itrgs, welde, wie beim erften Bante, alB „Rad)=

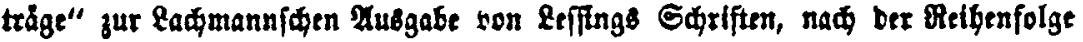
ber Bänte, angefügt werben follten. Th Gabe thanen ben \$las unter ben Beilagen bejes Banbes, in beffen zwet Mbtbeilungen, gegeben, unb zwar nad igren

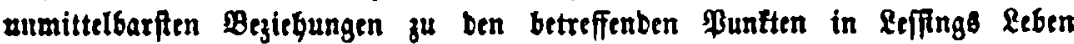

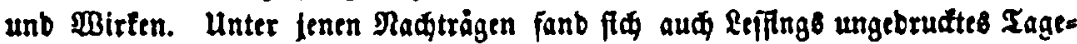

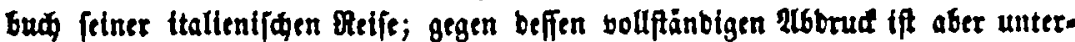
beffen son Seiten bes gegenwärtigen Gigentḩümer Betwabrung eingelegt, febod befien biograpkifde Benułung bereitwillig geftattet worben. Das OBanze aber wirb in ber eben begonnenen neuen, bon Gerrn v. MaItabn bejorgten, Aubs gabe ber jäuntliaben Gadriften lejing erideinen.

Gine befonbers bantbare Enadbnung serbienen hier bie fääbaren banb=

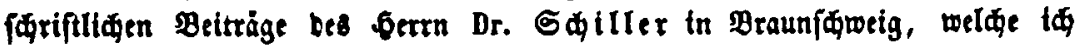
thetrs unter Danzers Papieren borfanb, theils birelt von 16m erfalten babe; bann aber bie ungebruaten Briefe von \$erter an Refing, welde \$err Me: glerungbratb s. Gerber in Grlangen mir zu überjenten bie Coüte gekgaft bat.

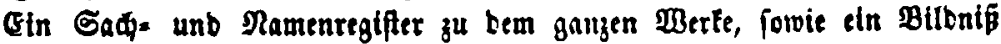
Refings wirb am Sdluffe ber zweiten $\mathfrak{A}$ btgeilung getiefert werben.

Breglad, im Auguft 1853.

G. E. Gubrauex. 